\title{
An inside view on pesticide policy
}

Ian L. Boyd ${ }^{*}$

University of St Andrews, College Gate, North Street, St Andrews KY16 9LB

\begin{abstract}
Author accepted manuscript for paper published on $30^{\text {th }}$ April 2018 Nature Ecology and Evolution | DOI: 10.1038/s41559-018-0557-8
\end{abstract}

European governments are poised to ban neonicotinoid pesticides. Insights from six years as a senior government advisor have led me to conclude that agricultural reform is urgently needed, beyond cycles of pesticide licensing and withdrawal.

Pesticides come and go. Since the introduction of organochlorines, like DDT and dieldrin, in the 1940s, successive classes of chemical pesticides have been licensed for agricultural use and then been withdrawn from use as unexpected environmental or health impacts have appeared. This is now a familiar cycle and neonicotinoids are the current incarnation of this pattern. As chief scientific adviser to the United Kingdom's Department of Food, Environment and Rural Affairs (DEFRA), I have observed aspects of the neonicotinoid story that are instructional for future pesticide management and for the science-policy interface in general.

New pesticides are typically licenced for use based on guidance written on the label of the container. This guidance is constructed from efficacy and safety testing conducted in specific circumstances but which cannot simulate all the conditions encountered by users. As demand for a new pesticide increases, growers develop farming systems and business structures that rely on it. But as unanticipated impacts and pest resistance begin to appear, community opposition to the pesticide grows, chemical companies scramble to develop 'less harmful' variants, and governments struggle to balance their obligations to food production and environmental responsibility. As the evidence base against the pesticide grows, governments withdraw licences for use, and growers are left to pick up the pieces.

This cyclical pattern applies the world over and is driven by two opposing mythologies. The first is that agricultural productivity will collapse without using pesticides at current levels ${ }^{1}$. If this is true it is because we have designed agriculture around these pesticides such that productivity relies on their presence, but it does not need to be like this. Pesticides are often over-used ${ }^{1}$ and the quest for yield maximisation ignores the fact that food production is highly inefficient ${ }^{2}$ and wasteful ${ }^{3}$. We also fail to fully exploit our knowledge of plant genetics, which could reduce pesticide reliance, and we are half-hearted in implementing innovative solutions that require no pesticides, such as vertical farming where crops can be grown in a biosecure environment. 
The second myth is that banning pesticides solves the problem. But historically, banning a pesticide class has typically created incentives to substitute a known problem with a set of new problems that take around 20 years to appear and be banned in turn. Here, I would like to shed light on the recent decision to further restrict neonicotinoid use in the UK.

Government science advisers are mostly involved in areas of science where there is a lot of uncertainty and this is typified by the issue of neonicotinoids. The UK government ministers always said they would be guided by the science about neonicotinoids. This was a bold statement. There are several problems associated with making science the sole guide to policy $^{3}$, one of which is that it can encourage people with a particular agenda, either overtly expressed or subliminal, to produce research biased towards their preferred outcome.

I saw this happen throughout the neonicotinoid story. Some studies referred to as "landmark" by the press were statistically underpowered and socially over-sold; confirmation bias was sometimes blatantly obvious and sometimes heavily veiled. Most studies failed to address the key question the government needed answered, which was whether neonicotinoids had a significant effect on non-target insects, especially bees, at the level of whole populations.

This may be an impossible question to answer and proxies of these effects might have to suffice. But the awkward truth about studies of the effects of neonicotinoids is that there has been an inverse relationship between statistical power and the relevance of the results to the key question ${ }^{4}$. Near-realistic field-based studies produced mixed and generally inconclusive results, and low levels of statistical significance rendered them largely uninformative. The results of lab studies were quite clear, but they did little more than confirm that neonicotinoid insecticides were poisonous to insects. Thus, much of the direct evidence produced did not help with making a policy decision.

Similar criticisms could be levelled at the regulatory studies used to support the licencing of neonicotinoids as pesticides. These studies were not open to scrutiny and I was never given access to them. The drive to avoid multiple jeopardy and to protect commercial confidentiality does nothing to promote transparency and trust in the regulatory system. Possibly as a result of this, I also saw that the agri-chemical and farming industries appeared to misunderstand the duty they have to promote transparency in how they supply and use pesticides. Too often, it seemed that, to them, the function of regulation was to protect their business interests rather than to deliver public goods.

Regulation does not work unless it is trusted. I suggest that the progressive increase in pesticide prohibition is symbolic of increasing distrust in current pesticide regulation. The rising tide of evidence, irrespective of its quality, also reflects this loss of trust. 
My view about neonicotinoids ultimately hinged on two key pieces of evidence. The first of these was almost incidental: neonicotinoids were appearing in places where they should never have been found. For example, field experiments could not be conducted properly because control plots often turned out to be contaminated. This pervasiveness amounted to evidence for much longer soil residence times and intrasoil transport than had been assumed. My own modelling of dose rates with different plausible half-lives of neonicotinoids in soils showed a high probability that there could be accumulation in soils.

The second line of evidence came from unpublished data showing that neonicotinoids had a significant positive effect on yields but that this effect was small compared with overall yield variability. I thought this was a very strange result. If this had been presented as evidence of efficacy then it would not have passed muster. I suspected that the controls in this case were also contaminated.

In such situations, no piece of evidence on its own is ever decisive, but there was a pattern developing. There had been increasing use of neonicotinoids in Britain since 2000. They were being used widely throughout the arable cereal industry and in some specialist crops like carrots, parsnips and sugar beet, not just on flowering crops like oilseed. The evidence was suggesting that the countryside was, in effect, being heavily dosed using prophylactic neonicotinoid seed dressings. Even farmers who chose not to use neonicotinoids, such as those farming organically, were likely to be benefitting because of this landscape-scale dosing. In addition, withdrawing neonicotinoids from use on flowering break crops like oilseed in 2013 may have had little protective effect for pollinators because the same fields were being used to grow cereals treated with neonicotinoids within the crop rotation cycle.

Of course, this was a hypothesis rather than a definitive, evidence-based story. Reliable data on soil accumulation was almost non-existent (or buried in inaccessible dossiers used to gain a licence for use), but the data on use rates was very clear. The Environment Agency had also begun to measure neonicotinoids at monitoring sites and were finding their presence sometimes in surprising places. If they were so pervasive and widespread then what were their indirect, diffuse effects on insect and soil invertebrate faunas? We had no idea.

My advice became that neonicotinoids were probably being used on scales outside the scope of their licence. Even if every individual farmer was using neonicotinoids according to the regulations, those regulations did not account for how many farmers were using them or how often they were being used.

Ultimately, government must attempt to balance concerns for the farming industry, food prices and the competitive edge of UK food production in global markets, with the effects of environmental damage. Neonicotinoids are an important chemical technology if used intelligently and sparingly and if this balance of risk is taken in to account. But the regulatory process tends to be a blunt instrument which is blunted 
further when given a political spin. We need to dampen down the wild swings between using chemicals like neonicotinoids almost without constraint on the one hand and banning their use altogether on the other hand. Neither is sensible. This calls for a much more evidence-driven, risk-based way of regulating the use of pesticides ${ }^{5}$.

However, a lesson for the scientific research community is that swathes of carefully controlled, peer-reviewed evidence ${ }^{5,6}$ is often uninfluential if it is not focussed on the key question which policy-makers seek to answer. Defining this question is critical to avoiding wasted effort. What may appear a sensible biological question will not always seem so sensible when confronted with the operational realities of regulation and the law ${ }^{3}$.

It remains possible that neonicotinoids are relatively benign and the risks from their use are proportionate to the benefits they provide. Uncertainty will always be a problem when making judgements about diffuse environmental impacts, but we can be much more certain about the fact that these diffuse effects are part of a farming system which needs overhaul and thorough reform. If further restricting, but not banning, neonicotinoids encourages genuine innovation and stops the next cycle of chemical abuse of the environment, then progress will have been made.

Author contributions

lan Boyd is Chief Scientific Adviser at the UK Department for Environment, Food and Rural Affairs. The views in this paper are the author's own.

Figure 1 | Evidence points to the presence of neonicotinoid pesticides across the UK landscape, vastly exceeding target areas. [Photo caption ok?]

\footnotetext{
${ }^{1}$ Lechnet, M. et al. 2017. Reducing pesticide use while preserving crop productivity and profitability on arable farms. Nature Plants 3, 17008, doi:10.1038/nplants.2017.8

2 Pimentel, D. \& Pimentel, M. 2003. Sustainability of meat-based and plant-based diets and the environment. The American Journal of Clinical Nutrition 78, 660S-663S. https://doi.org/10.1093/ajcn/78.3.660S.

${ }^{3}$ Houk. O. 2003. Tales from a troubled marriage: science and law in environmental policy. Science 302, 1936-1929.

${ }^{4}$ Godfray, H.C.J. et al. A restatement if the natural science evidence base coincering neonicotinoid insecticides and insect pollinators. Proceeding of the Royal Society B 281: 20140558. DOI: $10.1098 /$ rspb.2014.0558

${ }^{5}$ Milner, A.M. \& Boyd. I.L. 2017. Toward pesticidovigilance. Science 357, 1232-1234 DIO: 10.1126/science.aan2683.

${ }^{6}$ Sutherland, W.J. \& Wordley, C.F.R. 2017. Evidence complacency hampers conservation. Nature Ecology and Evolution 1: 1215-1216. DOI: 10.1038/s41559-017-0244-1.
} 